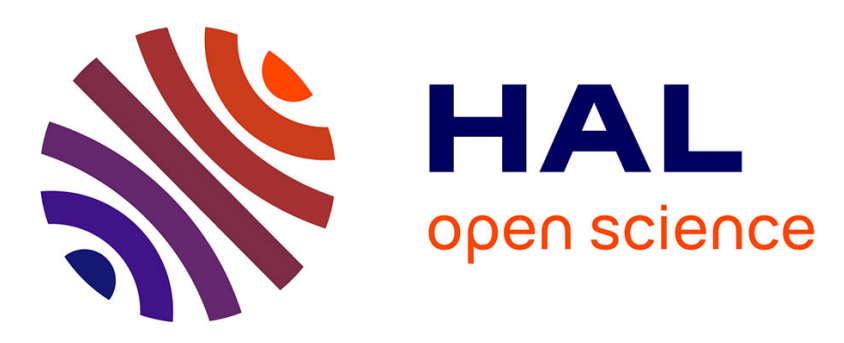

\title{
Chain extender effect of 3-(4-hydroxyphenyl)propionic acid/layered double hydroxide in biopolyesters containing the succinate moiety
}

Laura Sisti, Grazia Totaro, Annamaria Celli, Adam Marek, Vincent Verney, Fabrice Leroux

\section{To cite this version:}

Laura Sisti, Grazia Totaro, Annamaria Celli, Adam Marek, Vincent Verney, et al.. Chain extender effect of 3-(4-hydroxyphenyl)propionic acid/layered double hydroxide in biopolyesters containing the succinate moiety. New Journal of Chemistry, 2020, 44 (24), pp.10127-10136. 10.1039/C9NJ06322F . hal-02992462

\section{HAL Id: hal-02992462 \\ https://hal.science/hal-02992462}

Submitted on 20 Nov 2020

HAL is a multi-disciplinary open access archive for the deposit and dissemination of scientific research documents, whether they are published or not. The documents may come from teaching and research institutions in France or abroad, or from public or private research centers.
L'archive ouverte pluridisciplinaire HAL, est destinée au dépôt et à la diffusion de documents scientifiques de niveau recherche, publiés ou non, émanant des établissements d'enseignement et de recherche français ou étrangers, des laboratoires publics ou privés. 


\title{
Chain extender effect of 3-(4-hydroxyphenyl)propionic acid/layered double hydroxide in biopolyesters containing succinate moiety
}

\author{
Laura Sisti, ${ }^{a}$ Grazia Totaro, ${ }^{* a}$ Annamaria Celli, ${ }^{a}$ Adam A. Marek, ${ }^{b}$ Vincent Verney, ${ }^{c}$ and Fabrice Leroux ${ }^{c}$ \\ 3-(4-hydroxyphenyl)propionic acid, intercalated in $\mathrm{Mg}_{2} \mathrm{Al} /$ layered double hydroxide has been used as filler in biopolyesters containing succinate moiety, such \\ as poly(propylene succinate) (PPS), poly(butylene succinate-co-butylene adipate) (PBSA) and poly(butylene succinate) (PBS) with the aim of inducing an \\ effect similar to that of an increment of the molecular weight of matrices. The composites (1, 5 and 10 wt. \% of filler), have been prepared by a simple melt \\ blending procedure. X-ray diffraction analysis revealed the presence of intercalated structures in composites. From melt rheology measurements, a chain \\ extender effect of the filler, towards PBS, PPS and to some extent PBSA, was evident and proportional to the composition, producing a reinforcing role of the \\ filler towards the polymeric chains. Moreover, no gel-like structure was produced. Such findings can be useful in widening the processing window of \\ biopolyesters, in order to design multifunctional materials with adapted properties.
}

\section{Introduction}

The replacement of traditional plastic materials, such as polyethylene and polystyrene, by a variety of sustainable materials, such as poly(lactic-acid), poly(hydroxy alkanoates) and poly(butylene succinate), is a pressing need. However, in general it has been observed that the performances of the bio-based polymers must be enhanced in order to make them suitable to more demanding engineering applications. An inherent limitation is linked to their poor rheological properties, which limit their processing characteristics. Moreover, these materials are characterized by a very narrow range of processing temperatures and, in addition to this aspect, at high temperature polyesters can be exposed to undesired reactions such as hydrolysis, alcoholysis and thermal degradation, ${ }^{1,2}$ that can cause modification of intrinsic characteristics, such as the molecular weight.

A possible solution to exceed the limit of a small processing window is today faced with chain extenders, which can increase the molecular weight $(\mathrm{Mw})$ with consequent improving of melt viscosity, melt strength and mechanical properties. Typical chain extenders for polyesters, which contain $-\mathrm{OH}$ and $-\mathrm{COOH}$ groups, are bifunctional low-molecular weight chemicals, such as di-isocyanates, di-epoxides, bis-oxalines, di-anhydrides and bis-ketene acetals. ${ }^{3}$ For example, in literature acrylic epoxy resins, such as Joncryl ADR-4380, were found to increase $\mathrm{Mw}$ and elongational properties of recycled poly(ethylene terephthalate) (PET) ${ }^{4}$ and melt viscosity of poly(lactic acid)/poly(butylene succinate)/microcrystalline cellulose blends. ${ }^{5}$ Epoxy chain extenders were used for poly(lactic acid)/poly(butylene adipate-co-terephtalate) blends ${ }^{6}$ and epoxy functionalized poly(lactic acid) were employed for poly(lactic acid)/poly(butylene succinate-co-adipate) blends. ${ }^{7}$ However, some problems can occur, such as the release of the added molecules out of matrix with consequent environmental and health problems due to their toxicity. Furthermore, a relatively high amount of linear chain extender is needed to reach a significant increase in $\mathrm{Mw}$, and overdosing of the additive may lead to some over crosslinking reactions and possible gelation, which make the material unsuitable to be processed with regular extrusion or injection molding equipment. $^{2}$

Besides such classical chain extender systems, a new approach to improve the rheological behaviour involves hydrotalcyte-like compounds (HT), which belong to the large family of layered double hydroxides (LDHs). ${ }^{8-12}$ LDHs are versatile and multifunctional materials, thanks to their easiness of scaling-up preparation and functionalization through one pot synthesis, tunable composition and biocompatibility. They are advantageous in many fields of application as catalysts, anion exchangers, sorbents and scavengers for pollutants, additives and/or stabilizers in polymer formulations. ${ }^{13-15}$ The structure derives from brucite $\mathrm{Mg}(\mathrm{OH})_{2}$ with layers built from octahedra where the isomorphous substitution of some divalent cations by trivalent cations induces positive charges within the layers, that are counterbalanced by interleaved anions. A large variety of organic anions has been used to intercalate the space between the lamellae in order to organo-modify the hydroxyl platelets and to render them compatible with the polymer chains, as well as to confer specific properties to the matrix, according to the end-use properties required. $^{8-11,16-18}$ The use of organic/inorganic $(\mathrm{O} / \mathrm{I})$ platelets to improve the rheological properties of a polymer, almost corresponding to an increment of the molecular weight, represents an elegant alternative to the use of typical chain extender molecules mentioned above. LDHs are efficient even at low loadings and can enlarge the possibility of polymer use. Moreover, they also possess a huge 
possibility of functionalization and the final hybrid system can be exploited for a wide range of applications. In a previous work, ${ }^{17} 3$-(4-hydroxyphenyl)propionic acid (HPPA), intercalated in a $\mathrm{Zn}_{2} \mathrm{Al} / \mathrm{LDH}$ showed a significant chain extender effect against poly(butylene succinate) (PBS), proportional to the composition and without giving rise to gel-like structures by melt blending. In addition, HPPA has been reported to have antibacterial activity ${ }^{12,17,19}$ and a significant UV stabilizing effect, sustainable in time, ${ }^{20,21}$ therefore it is a good candidate to be used for the formulation of multifunctional materials, as also confirmed by a recent patent. ${ }^{22}$ In view of such promising results obtained with PBS, the chain extender effect of $\mathrm{Mg}_{2} \mathrm{Al} / \mathrm{HPPA}$ has been here investigated in poly(propylene succinate) (PPS) and poly(butylene succinate-co-adipate) (PBSA), and the data were compared to those obtained with PBS composites (Fig. 1 ), in order to evaluate if the LDH can exert a chain extender effect in a wider polyester family, containing succinate moiety. The use of $\mathrm{Mg}$ instead of $\mathrm{Zn}$, is more appropriate in terms of sustainability and biocompatibility. The natural LDH indeed has a cation composition $\mathrm{Mg} / \mathrm{Al}$ and is commonly used as anti-acid in commercial drugs.

PBS is one of the emerging biopolymers thanks to its eco-friendliness and biodegradability. ${ }^{23}$ PBS has yield strength similar to that of polypropylene, while its stiffness is between those of low-density and high-density polyethylene. ${ }^{23}$ However, some of its inherent shortcomings are a low melt strength and viscosity, as well as low gas barrier properties. Our research group studied PBS as the polymeric matrix in composite materials containing $\mathrm{LDH}^{8,9,12,16-18,20-22}$ graphene, ${ }^{24}$ lignocellulosic fibers ${ }^{25-28}$ and rice endosperm ${ }^{29}$ with the aim of improving its technical performances.

PBSA is a copolymer of PBS containing a potentially biobased comonomer: dimethyladipate. ${ }^{30}$ In this work, the molar feed ratio between succinate and adipate is $80 / 20$, because it was reported that this composition guarantees the best balance between biodegradation rate and thermomechanical properties. ${ }^{23}$ As compared to PBS, PBSA is more susceptible to biodegradation because of its lower crystallinity and higher flexibility of the polymer chains. Moreover, it can be processed into any yarnforms (melt blown, multifilament or monofilament, tape or split) for textile purposes and can be used for the fabrication of the more common injection molded items. However, the mechanical, barrier and thermal properties of the neat PBSA are still not sufficient to widen its end-use applications. ${ }^{31,32}$ To increase the performances of PBSA, composites have been prepared with polystyrene/titanium dioxide electrospun fibers, ${ }^{31}$ graphene oxide, ${ }^{32}$ organo-modified montmorillonite, ${ }^{33,34}$ halloysite nanotube, ${ }^{35}$ kenaf fibers, ${ }^{36}$ hydrolyzed collagen, ${ }^{37}$ rutile $\mathrm{TiO}_{2},{ }^{38}$ and hexadecylamine-modified layered zinc phenylphosphonate. ${ }^{39}$ PBSA composites with sorbitol and oleic acid modified LDHs have been reported by Chen et al.: the authors discussed about the biodegradation, which was hindered by LDH. ${ }^{40}$

On the other hand, literature is quite poor about PPS. It can be prepared starting from 1,3-propanediol, which can be conveniently obtained from biological fermentation. ${ }^{41}$ Contrary to PBS and PBSA, which are semicrystalline polymers, PPS is amorphous. It possesses a higher biodegradation rate, compared with PBS. The synthesis and characterization has been reported by Papageorgiou et al., ${ }^{42}$ Parcheta et al.. ${ }^{43}$ Umare et al. ${ }^{44}$ and Tsai et al. ${ }^{45}$ To widen the field of practical applications, PPS has been copolymerized for example with butylene succinate units by $\mathrm{Xu}$ et $a I^{41}$ More recently, PPS polyols were used for polyurethanes, ${ }^{46}$ and its thermal/mechanical properties were improved by adding various amounts of ester amide segments. ${ }^{47,48}$ To our knowledge, PPS composites have not been reported yet.

In view of the above consideration, the chain extender ability of $\mathrm{Mg}_{2} \mathrm{Al} / \mathrm{HPPA}$ is evaluated for the first time in PPS and PBSA melt blended composites, prepared with 1, 5 and $10 \mathrm{wt}$. \% of filler, through a combined characterization by melt rheology, X-ray diffraction and thermal analysis. In addition, PBS melt blended composites with the same filler amounts were prepared and similarly characterized, in order to evaluate if the LDH platelets can exert a chain extender effect in a wider polyester family, containing succinate moiety. The achievement of a better rheological response in the melt opens the potential application of such systems in the food packaging field (PBS), as mulching films for agriculture (PBSA) or medical devices (PPS). ${ }^{49}$

\section{Experimental}

\subsection{Chemicals}

1,3-propanediol (PD), 1,4-butanediol (BD), dimethyl adipate (DMA), dimethyl succinate (DMS), 3-(4hydroxyphenyl)propionic acid (HPPA), sodium hydroxide, magnesium nitrate $\mathrm{Mg}\left(\mathrm{NO}_{3}\right)_{2} \cdot 6 \mathrm{H}_{2} \mathrm{O}$, aluminum nitrate $\mathrm{Al}\left(\mathrm{NO}_{3}\right)_{3} \cdot 9 \mathrm{H}_{2} \mathrm{O}$ and titanium tetrabutoxide (TBT) were purchased from Aldrich Chemical. A 
commercial PBS specimen was obtained from NaturePlast $\left(\mathrm{MFI}\left(190^{\circ} \mathrm{C}, 2.16 \mathrm{~kg}\right)=4-6 \mathrm{~g} / 10 \mathrm{~min}\right.$; extrusion grade). All the materials were used as received.

\subsection{LDH Synthesis}

Hybrid LDHs were prepared by the coprecipitation method in the following way. Water solution (50 $\mathrm{mL})$ containing $0.0360 \mathrm{~mol}$ of $\mathrm{Mg}\left(\mathrm{NO}_{3}\right)_{2} \cdot 6 \mathrm{H}_{2} \mathrm{O}$ and $0.0180 \mathrm{~mol}$ of $\mathrm{Al}\left(\mathrm{NO}_{3}\right)_{3} \cdot 9 \mathrm{H}_{2} \mathrm{O}$ was dropped into a reactor containing $0.0722 \mathrm{~mol}$ of HPPA (4 times $\mathrm{Al}^{3+}$ initial input) in $100 \mathrm{~mL}$ of water under vigorous stirring. The $\mathrm{pH}$ of the mixture was maintained at a constant value of $9.5( \pm 0.1)$ through addition of $\mathrm{NaOH} 5 \mathrm{M}$ solution. After the coprecipitation $(3 \mathrm{~h})$, the suspension was stirred $3 \mathrm{~h}$ at ambient temperature. Both the ageing and the coprecipitation steps were carried out under nitrogen atmosphere in order to avoid the presence of carbonate. To eliminate the excess of the organic anion, the white solid material was then separated and submitted to 3 cycles of deionized water washing centrifugation. The sample code was $\mathrm{Mg}_{2} \mathrm{Al} / \mathrm{HPPA}$. X-ray diffractometry, FT-IR analysis and thermogravimetry of the organo-modified LDH were reported elsewhere. ${ }^{17}$

\subsection{Melt Polycondensation for the synthesis of polyesters}

2.3.1 Synthesis of poly(propylene succinate) (PPS). The procedure was previously described. ${ }^{50}$ Briefly, a round-bottomed, wide-neck glass reactor $(250 \mathrm{~mL}$ capacity) was charged with PD (34.4 $\mathrm{g}, 0.451 \mathrm{~mol})$, DMS $(50.7 \mathrm{~g}, 0.347 \mathrm{~mol})$ and TBT $\left(0.0681 \mathrm{~g}, 2.00 \cdot 10^{-4} \mathrm{~mol}\right)$. The molar ratio of PD:DMS was 1.3:1. The reactor was closed with a three-necked flat flange lid equipped with a heating band $\left(T=80{ }^{\circ} \mathrm{C}\right)$ and a torque-meter, indicating the viscosity of the reaction melt. The system was connected to a water-cooled condenser and immersed in a thermostatic salt-bath at $200{ }^{\circ} \mathrm{C}$, while the mechanical stirrer was set at $340 \mathrm{rpm}$. All methanol distilled off after almost $1 \mathrm{~h}$, then the lid was heated at $90{ }^{\circ} \mathrm{C}$ with the heating band and the reactor was connected to a liquid nitrogen-cooled condenser. Dynamic vacuum was then applied in 30 minutes down to 0.4 mbar, while the temperature was increased up to $230{ }^{\circ} \mathrm{C}$. When the torque of the melt was around $4 \mathrm{mN}$, a viscous, light brown and transparent melt was discharged from the reactor. The molecular structure of PPS, was confirmed by ${ }^{1} \mathrm{H}$ NMR (not shown) and coherent with literature. ${ }^{43}$

${ }^{1} \mathrm{H}$ NMR: $\left(400 \mathrm{MHz}, \mathrm{CDCl}_{3}, \delta\right): 1.92-2.01\left(\mathrm{~m}, 2 \mathrm{H} ; \mathrm{C}^{\mathrm{c}} \mathrm{H}_{2}\right), 2.53-2.68\left(\mathrm{~s}, 4 \mathrm{H} ; \mathrm{C}^{\mathrm{a}} \mathrm{H}_{2}\right), 4.05-4.22\left(\mathrm{t}, 4 \mathrm{H} ; \mathrm{C}^{\mathrm{b}} \mathrm{H}_{2}\right)$. The carbon labels were referred to the chemical structure reported in Fig. 1.

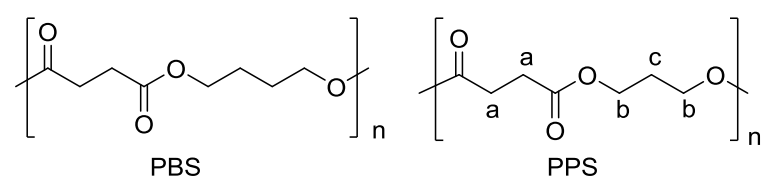<smiles>CC(=O)CC(=O)OCCCCOC(=O)CCCCC(=O)OCCCOC(C)(C)C</smiles>

PBSA

Fig. 1. Chemical Structures of PBS, PPS, PBS.

2.3.2 Synthesis of poly(butylene succinate-co-butylene adipate) (PBSA). PBSA was synthesized starting from $B D$, DMS and DMA, with a molar feed ratio of DMA:DMS $1: 4$, chosen from literature ${ }^{23}$ as the best composition in terms of thermomechanical properties. The procedure was reported in previous papers. ${ }^{51-53} \mathrm{BD}(40.0 \mathrm{~g}, 0.444 \mathrm{~mol})$, DMA (12.9 g, $\left.0.074 \mathrm{~mol}\right), \mathrm{DMS}(43.2 \mathrm{~g}, 0.296 \mathrm{~mol})$ and TBT $(0.0531 \mathrm{~g}$, $\left.1.56 \cdot 10^{-4} \mathrm{~mol}\right)$ as catalyst, were introduced into the glass reactor and the experimental set-up was as before for PPS. The temperature of the salt-bath was set at $200{ }^{\circ} \mathrm{C}$ and the stirring at $200 \mathrm{rpm}$. At the end 
of the first stage almost all methanol distilled off, and then a vacuum-temperature ramp was started (40 $\mathrm{min})$. The final temperature was $230{ }^{\circ} \mathrm{C}$ with a pressure of $0.4 \mathrm{mbar}$. At the end of the second stage, when the torque of the melt was around $6 \mathrm{mN}$, a viscous light yellow product was discharged from the reactor. The molecular structure of PBSA, as well as the ratio DMA-to-DMS, were confirmed by ${ }^{1} \mathrm{H}$ NMR (not shown) and the profile was coherent with literature. ${ }^{54}$

${ }^{1} \mathrm{H}$ NMR: $\left(400 \mathrm{MHz}, \mathrm{CDCl}_{3}, \delta\right): 1.60-1.68\left(\mathrm{~m}, 4 \mathrm{H} ; \mathrm{C}^{\mathrm{d}} \mathrm{H}_{2}\right), 1.68-1.78\left(\mathrm{~m}, 4 \mathrm{H} ; \mathrm{C}^{\mathrm{c}} \mathrm{H}_{2}\right), 2.29-2.36\left(\mathrm{~m}, 4 \mathrm{H} ; \mathrm{C}^{\mathrm{a}^{\prime}} \mathrm{H}_{2}\right)$, 2.60-2.65 (s, 4H; $\left.\mathrm{C}^{a} \mathrm{H}_{2}\right), 4.05-4.18\left(\mathrm{~m}, 4 \mathrm{H} ; \mathrm{C}^{\mathrm{b}} \mathrm{H}_{2}\right)$. The carbon labels were referred to the chemical structure reported in Fig. 1.

\subsection{Melt Blending}

PPS, PBSA, a commercial PBS and LDHs were vacuum dried overnight at $60{ }^{\circ} \mathrm{C}, 80{ }^{\circ} \mathrm{C}$ and $100{ }^{\circ} \mathrm{C}$, respectively. Their composites were obtained in melt extrusion process, using a co-rotating twin screw extruder Haake MiniLab Micro Compounder (Thermo Electron Corporation, Germany). The operating conditions used in the process were the following: temperature of $60^{\circ} \mathrm{C}$ for PPS and $120^{\circ} \mathrm{C}$ in the case of PBSA or PBS, a rotating speed of $100 \mathrm{rpm}$ over $3 \mathrm{~min}$. Polymers free of filler were processed as reference samples. Samples were named $X: \mathrm{Mg}_{2} \mathrm{Al} / \mathrm{HPPA}-\mathrm{Y}$, where $X$ was the polymer and $Y$ was the weight percentage of $\mathrm{LDH}$ hybrid $(1,5,10 \mathrm{wt}$. \%) respect to the polymer.

\subsection{Measurements}

${ }^{1}$ H NMR spectra were measured on a Varian Mercury 400 spectrometer, chemical shifts were reported in ppm downfield from TMS; the solvent used was $\mathrm{CDCl}_{3}$.

Molecular weight and polydispersity index were determined using gel permeation chromatography (GPC) performed in $\mathrm{CHCl}_{3}$ at ambient temperature, using HP 1100 Series apparatus with a PL gel $5 \mu \mathrm{m}$ Minimixed-C column and a refractive index detector. Polystyrene standards were used to prepare a calibration curve.

The X-ray powder diffraction (XRD) analysis of PPS, PBS, PBSA and the 10 wt. \% composites was performed using a PANalytical X'Pert PRO diffractometer with $\mathrm{Cu}-\mathrm{K} \alpha$ radiation and equipped with an $X^{\prime}$ 'Celerator detector (wavelength $\lambda$ of $1.54 \AA$ ). The $2 \theta$ plots of $X$-ray spectra were collected at room temperature, over $2 \theta$ range of 2.5 to $80.0^{\circ}$ with a step of $0.067^{\circ}$ and measurement time of $41 \mathrm{~s}$ for each step to get relative low intensity of noise.

Thermogravimetric analysis (TGA) was performed using a Perkin Elmer TGA7 apparatus in temperature range $50-900{ }^{\circ} \mathrm{C}$ with a heating rate of $10{ }^{\circ} \mathrm{C} / \mathrm{min}$, in a stream of nitrogen $(40 \mathrm{~mL} / \mathrm{min})$. The onset degradation temperatures ( $T_{\text {onset }}$ ) were taken from the intersections of the tangents of the initial points and the inflection points.

The calorimetric analysis (DSC) was carried out using a Perkin-Elmer DSC6. Measurements were performed under nitrogen flow. In the first step, the thermal history of samples (ca. $10 \mathrm{mg}$ ) was deleted by first heating from 40 to $150{ }^{\circ} \mathrm{C}$ at $20^{\circ} \mathrm{C} / \mathrm{min}$, kept at high temperature for 2 min and then cooled down to $-60{ }^{\circ} \mathrm{C}$ at $10{ }^{\circ} \mathrm{C} / \mathrm{min}$. After that, the $2^{\text {nd }}$ scan was performed and samples were analyzed by heating from $-60{ }^{\circ} \mathrm{C}$ to $150{ }^{\circ} \mathrm{C}$ at $10{ }^{\circ} \mathrm{C} / \mathrm{min}$. Both the temperature of crystallization $\left(T_{C}\right)$ and the enthalpy of crystallization $\left(\Delta \mathrm{H}_{\mathrm{C}}\right)$ were measured during the cooling scan, while the glass transition temperature $\left(\mathrm{T}_{\mathrm{g}}\right)$, the melting temperature $\left(T_{m}\right)$ and the enthalpy of fusion $\left(\Delta H_{m}\right)$ were measured during the $2^{\text {nd }}$ scan. $T_{g}$ was taken as the midpoint of the heat capacity increment associated with the glass-to-rubber transition.

Oscillatory Shear measurements were carried out with a dynamic mechanical spectrometer ARES (Rheometric Scientific TA Instruments). The samples were placed between two parallel plates with a diameter of $8 \mathrm{~mm}$ and the gap was set at $1 \mathrm{~mm}$. The range of frequency sweeps was from 0.1 to 100 $\mathrm{rad} / \mathrm{s}$. In all cases, the oscillatory shear stress amplitude was checked to ensure that all measurements were conducted within the linear viscoelastic domain. The shear dynamic measurements were carried out at a constant temperature of $60^{\circ} \mathrm{C}$ (PPS composites), $120^{\circ} \mathrm{C}$ (PBSA and PBS composites). The storage 
modulus $\left(G^{\prime}\right)$ and loss modulus $\left(G^{\prime \prime}\right)$ were monitored as a function of the frequency and the real component $\left(\eta^{\prime}=G^{\prime \prime} / \omega\right)$ against the imaginary component $\left(\eta^{\prime \prime}=G^{\prime} / \omega\right)$ of the complex viscosity were plotted in Cole-Cole representation.

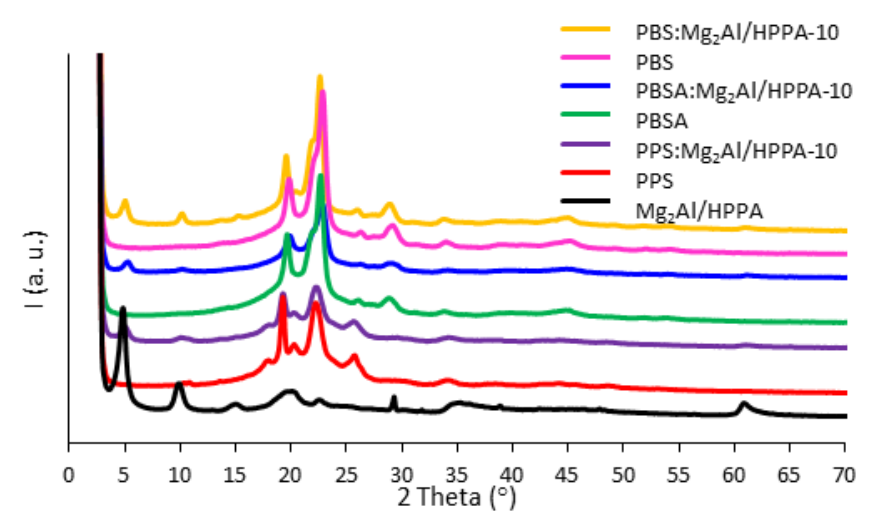

to $\mathrm{Mg}_{2} \mathrm{Al} / \mathrm{HPPA}$.

Fig. 2. XRD patterns of PBS, PPS, PBSA and their composites compared

\section{Results and discussion}

The chain extender effect of HPPA, hosted by LDH, previously reported by the authors, ${ }^{17,20,21}$ is here investigated in poly(propylene succinate) (PPS), poly(butylene succinate-co-butylene adipate) (PBSA) and poly(butylene succinate) (PBS) melt blended composites, prepared using 1, 5 and 10 wt. $\%$ of $\mathrm{Mg}_{2} \mathrm{Al} / \mathrm{LDH}$.

A full characterization of the filler, including FT-IR, X-ray diffraction and thermogravimetric analysis, has been reported elsewhere ${ }^{17}$ and demonstrated the organic modification of $L D H$. Briefly, the presence of the carboxylate stretching in infra-red profile of $\mathrm{Mg}_{2} \mathrm{Al} / \mathrm{HPPA}$, indicating the electrostatic interaction with the positive charged layers, suggested indeed the intercalation of the anion inside the host structure. This was confirmed by XRD, because of an enlargement of the host interlayer space up to $17.4 \AA$, due to HPPA. It is possible that the anion molecules are arranged by opposing their $\mathrm{COO}^{-}$terminal groups on two adjacent hydroxyl layers and by developing a $\pi-\pi$ intermolecular interaction, already reported for similar systems. ${ }^{55}$ The experimental chemical composition resulted $\left[\mathrm{Mg}_{0.66} \mathrm{Al}_{0.33}(\mathrm{OH})_{2}\right]\left(\mathrm{HPPA}^{-}\right)_{0.59} 0.56 \mathrm{H}_{2} \mathrm{O}$. The anion and water contents were estimated by observing the degradation losses from TGA, but the organic content was overestimated because of an overlapping with the $\mathrm{Mg}-\mathrm{OH}$ loss.

The molecular weights of all the polymeric samples have been measured by GPC and they are reported in Table 1: quite similar values within each series can be noted, therefore the melt blending occurs without degradation phenomena.

To evaluate the dispersion of the filler into the biopolyesters, XRD analysis was conducted on the composites containing the highest amount of $\mathrm{Mg}_{2} \mathrm{Al} / \mathrm{HPPA}$ (i.e. highest diffracting volume of filler) and the composite constituents, i.e. the homopolymers, the copolymer and the pristine LDH, for comparison (Fig. 2). At low angle, a diffraction line ascribable to the pristine LDH layered organization is visible, meaning that the basal spacing remains constant after polymer processing and thus that the polymer chains are not able to diffuse inside the filler gallery. This results in a "non-miscible" structure, most probably because of the blending and shearing procedure, not strong enough to favour a complete exfoliation of the platelets. PBS profile presents diffraction lines at $2 \theta=19.6,21.7,22.6$, and $28.9^{\circ}$ which could be assigned to (020), (021), (110) and (111) planes of PBS structure, respectively ${ }^{8,56}$ and are typical for a PBS crystal in the monoclinic unit cell. ${ }^{5}$ Its composite presents the same signals related to the polymer: the associated full width of height middle (FWHM), as well as the diffraction peak positions after incorporation of the hybrid O/I filler, remains unchanged. This means that the filler dispersion impacts on neither the crystallinity of PBS nor its coherence length, i.e. size of the crystallized domain. ${ }^{57}$ The diffraction peaks of PBSA are observed at $2 \theta=19.8,21.7,22.8^{\circ}$, coherent with those previously reported ${ }^{32,35}$ and suggesting that the crystal structure is that of PBS. In the case of PBSA:Mg $2 \mathrm{Al} / \mathrm{HPPA}-10$, the position of the peaks, corresponding to the crystalline structure of PBS units, is not altered. However, the relative intensity is diminished indicating a decrease in crystallinity but associated to an efficient level of dispersion of filler within PBSA. 
PPS presents diffraction lines at $2 \theta=10.6,10.8,19.2$, and $22.6^{\circ}$. The profile agrees with the literature ${ }^{41,42}$ even if the crystal lattice parameters have not been reported so far. However, for polymers with an odd number of methylene groups in their backbone, the unit cell is expected to be orthorhombic, in contrast to those with an even number of methylene groups, crystallizing in a monoclinic symmetry. ${ }^{42}$ In the case of its composite with $\mathrm{O} / \mathrm{I}$ LDH filler, the positions of the polymer diffraction lines remain similar with an intensity strongly diminished, indicating again a decrement of the degree of crystallinity and, then, a good level of dispersion of the hybrid filler within the polymer. Indeed smaller crystallized polymer domains are indicative of their interfacial interaction with the lamellar fillers, most probably at the meso-scale taking the dimension of the domains (FWHM of the corresponding diffraction peaks).

Fig. 3 shows a possible model structure of the materials prepared. Possibly, the interfacial interaction between polyester chains and the organo-modified LDH platelets may occur through: i) a jamming structure with strong attrition between tethered HPPA molecules and polyester chains; ii) weak interaction through hydroxyl bearing HPPA molecules adsorbed onto LDH and from their edges and carboxylic telechelic function present in the polyester end-chain; iii) crosslinking effect (which is not observed by rheology).

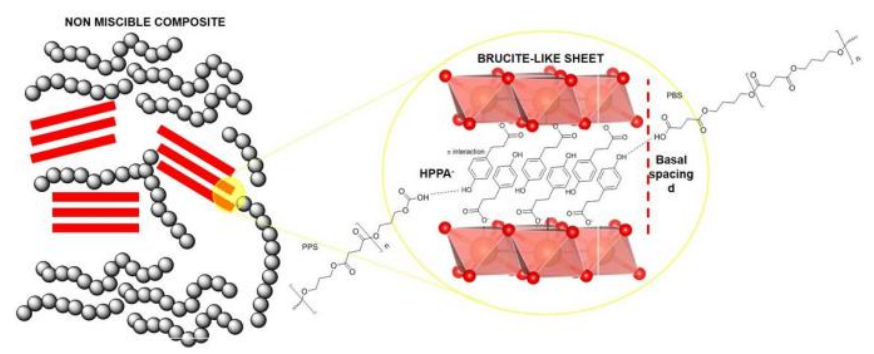

Fig. 3. Possible model structure of the materials prepared.

The results of DSC analysis are reported in Table 1. PBS and PBSA are semicrystalline, instead of PPS, which is amorphous. PBSA presents lower crystallinity respect to PBS. No significant effects of nanoclays on the thermal properties of the polymeric matrixes are evident. It can be noted that $T_{m}$ values of the composites remain constant at 115 and $94{ }^{\circ} \mathrm{C}$ for PBS and PBSA, respectively. The crystallization temperatures, located around $85^{\circ} \mathrm{C}$ (PBS series) and $49{ }^{\circ} \mathrm{C}$ (PBSA series), as well as the glass transition temperatures, located around $-30^{\circ} \mathrm{C}$ (PBS series) and $-47^{\circ} \mathrm{C}$ (PBSA series) do not change as well. The peak melting shapes (Fig. 4a and $4 \mathrm{~b}$ ) are similar respect to pristine PBS and PBSA. The small melting peak located before the main endothermic peak present in all heating scans is usually called the "annealing peak" as reported in many other semi-crystalline polymers. ${ }^{58}$ Concerning PPS composites, all the samples are amorphous in the second scan and no significant differences are evidenced: $T_{g}$ values of composites are similar to that of the homopolymer $\left(-34^{\circ} \mathrm{C}\right)$. During the first heating scan, however, a melting peak $\left(\Delta \mathrm{H}_{\mathrm{m}} \approx 26 \mathrm{~J} / \mathrm{g}\right)$ is observed indicating the ability of PPS to crystallize: PPS and PPS:Mg ${ }_{2} \mathrm{Al} / \mathrm{HPPA}-1$ show melting endothermic peaks at $50{ }^{\circ} \mathrm{C}$, which decrease down to $46{ }^{\circ} \mathrm{C}$ with higher amount of filler, highlighting somehow an interaction filler/polymer. Glass transition temperature of PPS, as well as the thermal data of PBSA and PBS are in agreement with literature. ${ }^{8,12,17,31,32,43}$ Some authors report a nucleating effect of the filler toward the matrix ${ }^{35}$ in PBSA/organo-modified MMT (Cloisite 15A) while in similar PBSA/MMT systems (Cloisite 30B), others observe a decrease in crystallinity degree with the inorganic phase incorporation. ${ }^{34}$

Regarding PBS/LDH systems, slight differences in crystallization rate and $T_{g}$ were reported, this for composites prepared by either melt blending ${ }^{16}$ or by in situ polymerization. ${ }^{17}$

Concerning the thermal stability, the thermogravimetric curves (Fig. 5-7) show a main decomposition step between $300-460{ }^{\circ} \mathrm{C}$ for all the series. The organo-modified filler determines a decrease in thermal stability quite proportional to the composition in all samples, as it can be observed by the $T_{\text {onset }}$ (Table 1). This phenomenon is attributed to the metals within the lamellae and/or the water released during the decomposition, which can catalyze the degradation of the polymer. However, the thermal stability is high for all the samples. Decreased stability has been reported for PBSA/LDH samples, ${ }^{40}$ for PBS/LDH nanocomposites,, ,12,16-18,20,21,59 as well as for analogous systems, such as poly(propylene carbonate)/MgAl$\mathrm{LDH}$, poly( $\varepsilon$-caprolactone)/LDH and poly(lactic acid): $: \mathrm{n}_{3} \mathrm{Al} / \mathrm{LDH}$ nanocomposites. ${ }^{60-62}$ 
Table 1. GPC, DSC and TGA results of PBS, PBSA, PPS and their nanocomposites.

\begin{tabular}{|c|c|c|c|c|c|c|c|c|c|}
\hline Sample & $\begin{array}{c}\mathrm{Mw} \\
\left(\times 10^{-3}\right)^{\mathrm{a})}\end{array}$ & $P D I^{a)}$ & $\begin{array}{c}\mathrm{T}_{\mathrm{g}} \\
\left({ }^{\circ} \mathrm{C}\right)^{\mathrm{b})}\end{array}$ & $\begin{array}{c}\Delta \mathrm{C}_{\mathrm{p}} \\
\left(\mathrm{J} / \mathrm{g}^{\circ} \mathrm{C}\right)^{\mathrm{b})}\end{array}$ & $\begin{array}{c}\mathrm{T}_{\mathrm{C}} \\
\left.\left({ }^{\circ} \mathrm{C}\right)^{\mathrm{C}}\right) \\
\end{array}$ & $\begin{array}{l}\Delta \mathrm{H}_{\mathrm{C}} \\
(\mathrm{J} / \mathrm{g})\end{array}$ & $\begin{array}{c}\mathrm{T}_{\mathrm{m}} \\
\left({ }^{\circ} \mathrm{C}\right)^{\mathrm{b})}\end{array}$ & $\begin{array}{c}\Delta \mathrm{H}_{\mathrm{m}} \\
(\mathrm{J} / \mathrm{g})^{\mathrm{b})}\end{array}$ & $\begin{array}{l}T_{\text {onset }} \\
\left({ }^{\circ} \mathrm{C}\right)^{d)} \\
\end{array}$ \\
\hline PBS & 41 & 2.7 & -31 & 0.11 & 85 & 63 & 115 & 47 & 388 \\
\hline PBS:Mg ${ }_{2} \mathrm{Al} / \mathrm{HPPA}-1$ & 45 & 2.4 & -30 & 0.19 & 85 & 60 & 115 & 47 & 379 \\
\hline PBS:Mg 2 Al/HPPA-5 & 52 & 2.5 & -30 & 0.16 & 85 & 56 & 115 & 45 & 360 \\
\hline PBS:Mg 2 Al/HPPA-10 & 53 & 2.1 & -32 & 0.13 & 85 & 51 & 115 & 43 & 353 \\
\hline PBSA & 39 & 2.0 & -47 & 0.27 & 49 & 46 & 94 & 40 & 379 \\
\hline PBSA:Mg ${ }_{2} \mathrm{Al} / \mathrm{HPPA}-1$ & 42 & 2.0 & -47 & 0.20 & 48 & 46 & 94 & 41 & 370 \\
\hline PBSA:Mg ${ }_{2} \mathrm{Al} / \mathrm{HPPA}-5$ & 46 & 2.0 & -47 & 0.15 & 48 & 44 & 94 & 38 & 353 \\
\hline PBSA:Mg ${ }_{2} \mathrm{Al} / \mathrm{HPPA}-10$ & 50 & 2.1 & -47 & 0.18 & 48 & 47 & 94 & 40 & 346 \\
\hline $\mathrm{PPS}^{\mathrm{e})}$ & 45 & 2.2 & -34 & 0.45 & / & / & / & / & 380 \\
\hline PPS:Mg ${ }_{2} \mathrm{Al} / \mathrm{HPPA}^{\mathrm{f}}{ }^{\mathrm{f}}$ & 49 & 2.4 & -35 & 0.56 & / & / & / & / & 375 \\
\hline PPS:Mg ${ }_{2} \mathrm{Al} / \mathrm{HPPA}^{-5^{\mathrm{g})}}$ & 50 & 2.4 & -34 & 0.46 & / & / & / & / & 373 \\
\hline PPS:Mg ${ }_{2} \mathrm{Al} / \mathrm{HPPA}-10^{\mathrm{h})}$ & 47 & 2.3 & -34 & 0.37 & l & I & 1 & I & 355 \\
\hline
\end{tabular}

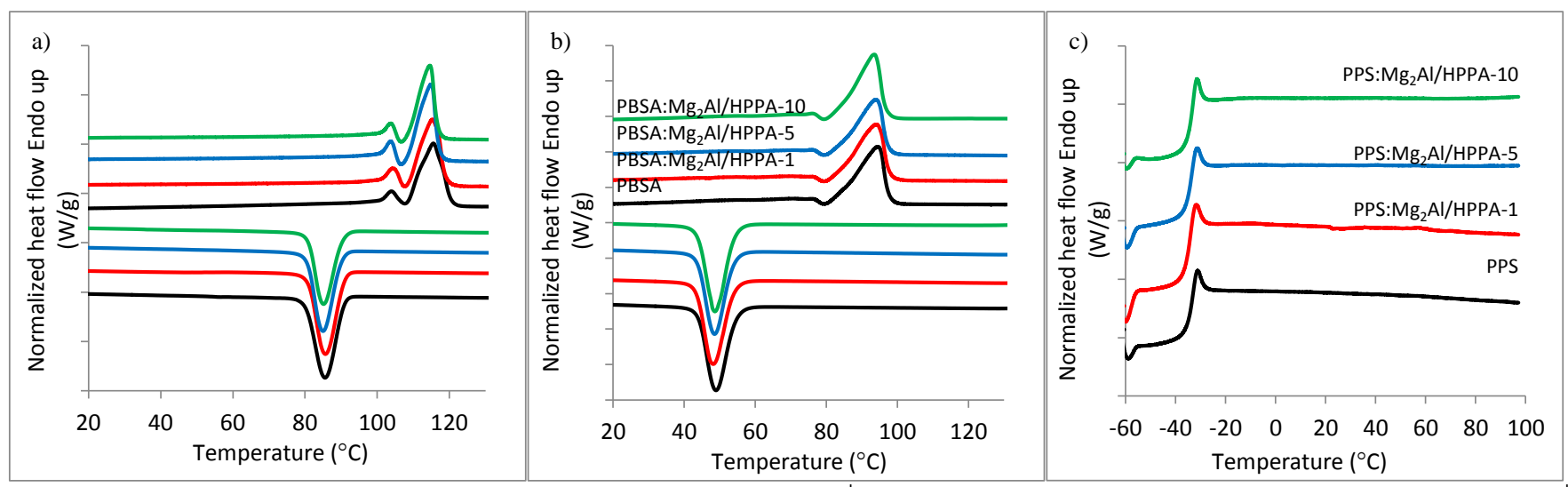

Fig. 4. DSC thermograms of a) PBS and its composites (cooling scan and $2^{\text {nd }}$ heating scan); b) PBSA and its composites (cooling scan and $2^{\text {nd }}$ heating scan); c) PPS and its composites ( $2^{\text {nd }}$ heating scan).

The study of rheological properties of nanocomposites under molten state allows in getting information about their processability and the structure-property relationship, because the melt rheological behavior is affected by the interface as well as by the nanostructure. The variation of the complex viscosity $\left|n^{*}\right|$ vs. $\omega$ of the materials prepared is shown in Fig. 8a-c. An increase is observed for all composites respect to the homopolymer, indicating an increment of the "apparent" molecular weight of the polymer. This is normally attributed to a lowering of the damping coefficient $\tan \delta\left(=G^{\prime \prime} / G^{\prime}\right)$ in the low- $\omega$ range, which in turn is due to some restriction in chains movement at the interface filler/polymer. As a rule, the cause of such flow restriction of the polymer chains is an increase in the chain dimension, until it reaches a transition from liquid (Newtonian polymer) to gel-like structure. ${ }^{11}$ However, being the slope related to the power-law tendency for $\left|\eta^{*}\right|$ almost unchanged after the introduction of LDHs, this demonstrates that the decrease in relaxation is due to an extension of the polymer chains, not to a network formation, that would have been resulting from crosslinking reactions. ${ }^{11}$ Some data fluctuations at low- $\omega$ region are visible and they can be due to thermomechanical degradation. The terminal zone indeed is very sensitive because the polymer has enough time to respond to the stress imposed on the melt. Moreover, we are close to the limit of sensitivity of the torque transducer, therefore some noise of the equipment can also occur. The extension of the polymer chains is further highlighted by using the Cole-Cole formalism to plot the rheological data. It is a complex plane representation $\left(\eta^{\prime \prime}-\eta^{\prime}(\omega)\right)$ which allows a clear visualization of slight changes in molecular weight and molecular weight distribution that may come from the addition of filler. In Fig. 8d-f, a semi-circle was observed in all the composites prepared and this was associated to a Newtonian behaviour. The convex downward semi-circle profile at $x$-intercept, $\eta$ " which tends to 0 , corresponds to the Newtonian zero-shear viscosity $\eta_{0}{ }_{0}$ at $\omega \rightarrow 0$ in the terminal zone and is related to an "apparent" $\mathrm{Mw}$ according to the empirical relationship:

$\eta_{0}^{\prime}=\mathrm{KMw}^{3.4}$ 
Newtonian zero-shear viscosity $\eta_{0}^{\prime}$ values are higher in composites respect to the pristine polymer for all the series.

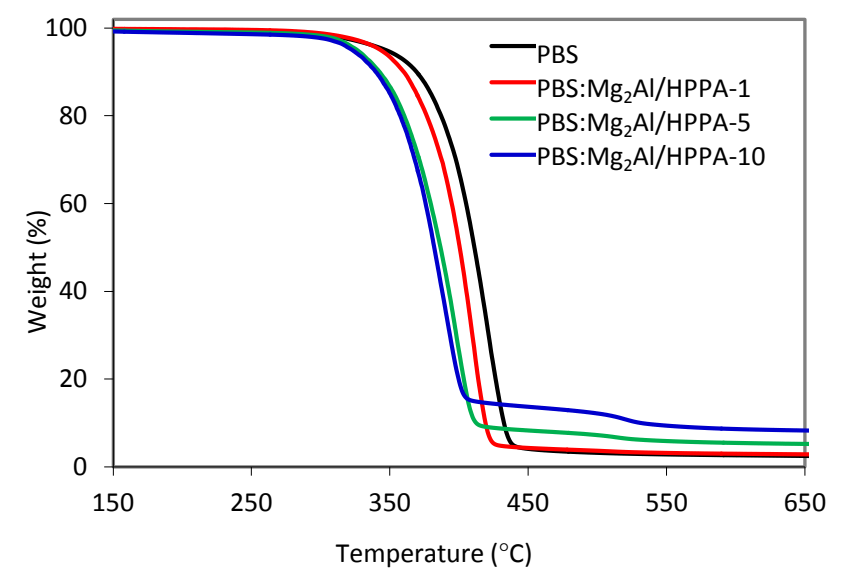

Fig. 5. Thermogravimetric curves of PBS and its composites.

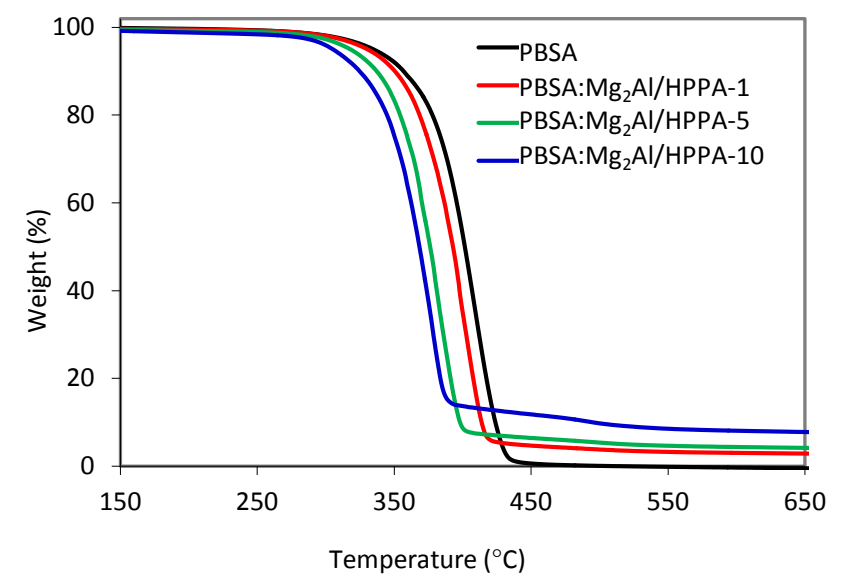

Fig. 6. Thermogravimetric curves of PBSA and its composites.

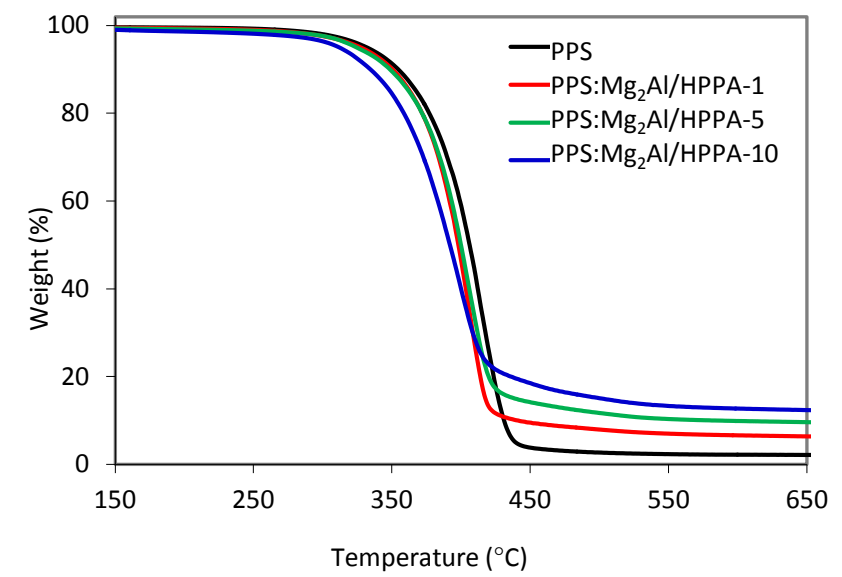


Fig. 7. Thermogravimetric curves of PPS and its composites.

By comparing the results of PBS samples with previous reported ones, ${ }^{8-12,16-18,20,21}$ it can be deduced that melt blending, even in the case of non-miscible composite polymer structure, is an effective and simple method to obtain composites. The filler indeed may still exert a tunable chain extender effect, proportional to its loading. HPPA, hosted by LDH, confirms such chain extender effect as well. It is interesting since intercalated and exfoliated polymer nanocomposite structures are difficult to reproduce as well as to be scaled-up. Moreover, it is important to point out that the materials prepared do not show network formation. This is important because usually, when gel-like structures are present, a strong shearing is required to attain a high performing extrusion, but this can be deleterious for the polymer structure, besides the obvious and undesired increase of costs. In comparison to PBS composites, those based on the copolymer PBSA, present modest zero shear viscosity values, but still increasing as a function of the LDH filler loading and always superior to the copolymer itself. In literature, melt rheology experiments of PBSA/Cloisite 30B (C30B) composites were reported by Ray et al. ${ }^{34}$ C30B was modified with quaternary ammonium salt and a pseudo-solid-like behavior was found with 6 and 9 wt.\% compositions. The authors reported that exfoliated and/or disordered intercalated silicate layers produce a network-type structure: the system is highly elastic as in rubber-toughened polymers, where rubber particles form a percolating network resulting in a solid-like behavior of the blend. ${ }^{34}$ Chiu et al. $^{35}$ prepared similar systems but with Cloisite 15A (C15A) or halloysite nanotubes (HNT). They found an increase in $\eta^{*}$ and $\mathrm{G}^{\prime}$ proportional to the loading of C15A. With 5 wt.\% loading of C15A a pseudo-network structure was observed, unlike the HNT-added composite system. However, beyond this concentration, exfoliated and or disordered intercalated silicate layers form a network-type structure rendering the system highly elastic as revealed by the low-frequency plateau.

The chain extender effect exerted by the hybrid filler toward PBS, PPS and to some extent PBSA, is evident and is representative of a reinforcing role of the modified-LDH. This is due to a good dispersion of the filler resulting in an increase of Newtonian zero-shear viscosity $\eta^{\prime}{ }_{0}$ and complex viscosity $|\eta *|$. This is observed even in absence of an intimate mixing between the polymer chains and the filler platelet system. Such behavior can be definitely related to an interface between the organo-clay and aliphatic polyester chains strongly developed at the meso-scale. However, some attritive reactions between the hydroxyl group from HPPA and the carbonyl functions of polyester cannot be ruled out. Therefore, the role of HPPA, hosted by the LDH, reported in previous works, ${ }^{12,17,20,21}$ is confirmed. The Newtonian zeroshear viscosity increment is proportional to the loading content, making this technology a suitable solution in endowing PBS and PPS with enhanced properties. However due to the modest enhancement observed unless for PBS or using higher mass loading for the two other polyesters (up to 10 wt. \%), the LDH filler technology extended to this polyester family is not optimized yet and improvements are needed to further investigate the thermomechanical properties as what has been done on the composite hit, LDH/HPPA:PBS. ${ }^{21}$

For PPS, the idea was to evaluate a potential upgrading of its properties. PPS has not been exploited because of a lack of properties and if LDH/HPPA can exerts a chain extension on it, then it can become an interesting polymer as biobased propanediol is easier to obtain than butanediol.

\section{Conclusions}

Composites based on $\mathrm{Mg}_{2} \mathrm{Al} / \mathrm{HPPA}$ and biopolyesters containing succinate moiety such as PBS, PBSA and PPS have been prepared by a simple melt blending procedure. X-ray diffraction analysis revealed the presence of intercalated, non-miscible structures at the nanometric scale. All the composites presented high thermal stability and no significant changes have been highlighted in thermal behaviour by DSC experiments. From melt rheology measurements, a chain extender effect of the filler toward PBS, PPS and to some extent PBSA, is evident and it is proportional to the loading, suggesting a large meso- to small macro-interfacial interaction between polymer chains and small O/I LDH filler domains. This result underlines a reinforcing role of the filler towards the polymeric chains. It can be concluded that melt blending is an effective and simple method to obtain reproducible biocomposites without producing gel- 
like structure. Such findings can be useful in widening the processing window of biopolyesters, in order to design multifunctional materials with adapted properties.

\section{Conflicts of interest}

There are no conflicts to declare.
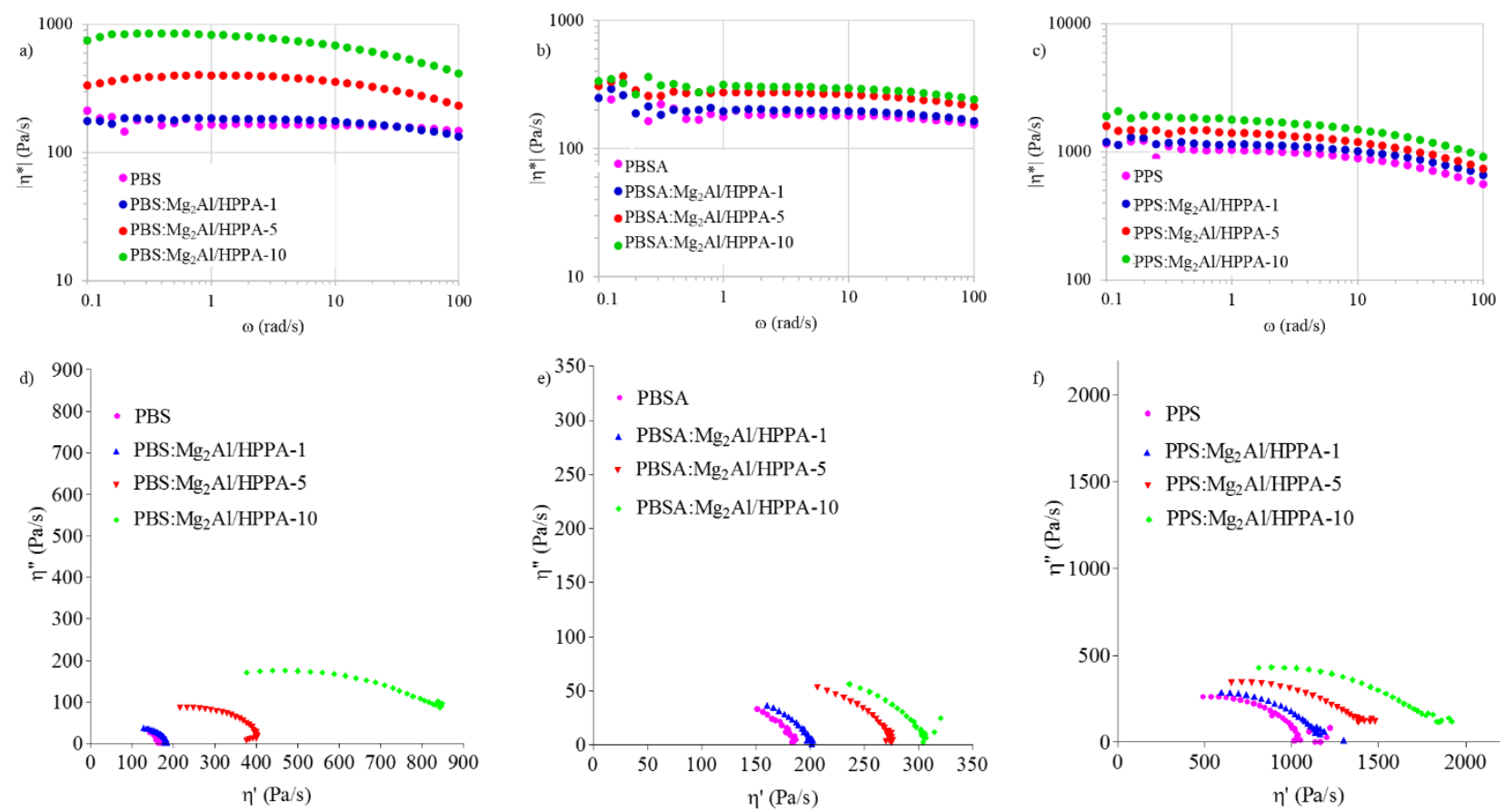

Fig. 8. Complex viscosity versus frequency of a) PBS and its composites, b) PBSA and its composites, c) PPS and its composites; Cole-Cole plots of d) PBS and its composites, e) PBSA and its composites, f) PPS and its composite.

\section{Notes and references}

[1] Zia KM, Noreen A, Zuber M, Tabasum S, Mujahid M. Recent developments and future prospects on bio-based polyesters derived from renewable resources: A review. Int. J. Biol. Macromol. 2016;82:1028-1040.

[2] Frenz V, Scherzer D, Villalobos M, Awojulu AA, Edison M, van der Meer R. Multifunctional polymers as chain extenders and compatibilizers for polycondensates and biopolymers, ANTEC 2008;1682-1686.

[3] Yu T, Li Y. Biodegradable Poly(Lactic Acid) and Its Composites. In: Vijay Kumar Thakur, Manju Kumari Thakur (ed) Handbook of Sustainable Polymers: Processing and Applications, CRC Press, Taylor and Francis Group, Boca Raton FL, 2016, pp 857-891.

[4] Makkam S, Harnnarongchai W. Rheological and Mechanical Properties of recycled PET modified by reactive extrusion. Energy Procedia 2014;56:547-553.

[5] Cao Z, Lu Y, Zhang C, Zhang Q, Zhou A, Hu Y, et al. Effects of the chain extender content on the structure and performance of poly(lactic acid)-poly(butylene succinate)-microcrystalline cellulose composites. J. Appl. Polym. Sci. 2017;134(22):44895(1-8).

[6] Dong W, Zou B, Yan Y, Ma P, Chen M. Effect of Chain-Extenders on the properties and hydrolytic degradation behavior of the poly(lactide)/poly(butylene adipate-co-terephthalate) blends. Int. J. Mol. Sci. 2013;14(10):20189-20203.

[7] Mirzadeh A, Ghasemi H, Mahrous F, Kamal MR. Reactive extrusion effects on rheological and mechanical properties of poly(lactic acid)/poly[(butylene succinate)-co-adipate]/epoxy chain extender blends and clay nanocomposites. J. Appl. Polym. Sci. 2015;132(48):42664(1-11).

[8] [8] Totaro G, Sisti L, Celli A, Askanian H, Verney V, Leroux F. Poly(butylene succinate) bionanocomposites: a novel bio- organomodified layered double hydroxide for superior mechanical properties. RSC Adv. 2016;6:4780-4791.

[9] Leroux F, Dalod A, Hennous M, Sisti L, Totaro G, Celli A, et al. X-ray diffraction and rheology cross-study of polymer chain penetrating surfactant tethered layered double hydroxide resulting into intermixed structure with polypropylene, poly(butylene)succinate and poly(dimethyl)siloxane. Appl. Clay Sci. 2014;100:102-111.

[10] Coelho C, Stimpfling T, Leroux F, Verney V. Inorganic-Organic hybrid materials based on amino acid modified hydrotalcites used as UV-absorber fillers for polybutylene succinate. Europ. J. Inorg. Chem. 2012;2012(32):5252-5258. 
[11] Hennous M, Derriche Z, Privas E, Navard P, Verney V, Leroux F. Lignosulfonate interleaved layered double hydroxide: A novel green organoclay for bio-related polymer. Appl. Clay Sci. 2013;71:42-48.

[12] Totaro G, Sisti L, Celli A, Aloisio I, Di Gioia D, Marek A, et al. Dual chain extension effect and antibacterial properties of biomolecules interleaved within LDH dispersed into PBS by in situ polymerization. Dalton Trans. 2018;47(9):3155-3165.

[13] Rossi C, Schoubben A, Ricci M, Perioli L, Ambrogi V, Latterini L, et al. Intercalation of the radical scavenger ferulic acid in hydrotalcite-like anionic clays. Int. J. Pharm. 2005;295:47-55.

[14] Yamada H, Tamura K, Watanabe Y, lyi N, Morimoto K. Geomaterials: their application to environmental remediation. Sci. Technol. Adv. Mater. 2011;12(6):064705(13pp).

[15] Oh JM, Choi SJ, Lee GE, Han SH, Choy JH. Inorganic drug-delivery nanovehicle conjugated with cancer-cell-specific ligand. Adv. Funct. Mater. 2009;19(10):1617-1624.

[16] Sisti L, Totaro G, Fiorini M, Celli A, Coelho C, Hennous M, et al. Poly(butylene succinate)/layered double hydroxide bionanocomposites: Relationships between chemical structure of LDH anion, delamination strategy, and final properties. J. Appl. Polym. Sci. 2013;130(3):1931-1940.

[17] Totaro G, Sisti L, Celli A, Hennous M, Askanian H, Verney V, et al. Chain extender effect of 3-(4-hydroxyphenyl)propionic acid/layered double hydroxide in PBS bionanocomposites. Europ. Polym. J. 2017;94:20-32.

[18] Marek AA, Verney V, Taviot-Gueho C, Totaro G, Sisti L, Celli A, et al. Outstanding chain-extension effect and high UV resistance of polybutylene succinate containing amino-acid-modified layered double hydroxides, Beilstein J. Nanotechnol. 2019;10: 684695.

[19] Sun J, Lin Y, Shen X, Jain R, Sun X, Yuan Q, et al. Aerobic biosynthesis of hydrocinnamic acids in Escherichia coli with a strictly oxygen-sensitive enoate reductase. Metab. Eng. 2016;35:75-82.

[20] Marek AA, Verney V, Totaro G, Sisti L, Celli A, Leroux F. Composites for " white and green " solutions: coupling UV resistance and chain extension effect from poly(butylene succinate) and layered double hydroxides composites. J. Solid State Chem. 2018;268:9-15.

[21] Marek AA, Verney V, Totaro G, Sisti L, Celli A, Bozzi Cionci N, et al. Organo-modified LDH fillers endowing multi-functionality to bio-based poly(butylene succinate): an extended study from the laboratory to possible market. Appl. Clay Sci. 2020;188:105502.

[22] Leroux F, Verney V, Sisti L, Celli A, Totaro G, WO2016189228 A1, PCT/FR2016/051189, 12/01/2016.

[23] Sisti L, Totaro G, Marchese P. PBS Makes its Entrance into the Family of Biobased Plastics. In: Susheel Kalia, Luc Averous (ed) Biodegradable and Biobased Polymers for Environmental and Biomedical Applications, Scrivener Publishing, Wiley, 2016, pp 225-273.

[24] Sisti L, Belcari J, Mazzocchetti L, Totaro G, Vannini M, Giorgini L, et al. Multicomponent reinforcing system for poly(butylene succinate): Composites containing poly(L-lactide) electrospun mats loaded with Graphene. Polym. Test. 2016;50:283-291.

[25] Sisti L, Kalia S, Totaro G, Vannini M, Negroni A, Zanaroli G. Enzymatically treated curaua fibers in poly(butylene succinate)-based Biocomposites. J. Environ. Chem. Eng. 2018;6(4):4452-4458.

[26] Frollini E, Bartolucci N, Sisti L, Celli A. Biocomposites based on poly(butylene succinate) and curaua: mechanical and morphological properties. Polym. Test. 2015;45:168-173.

[27] Thakur K, Kalia S, Kaith BS, Pathania D, Kumar A, Thakur P, et al. The development of antibacterial and hydrophobic functionalities in natural fibers for fiber-reinforced composite materials. J. Environ. Chem. Eng. 2016;4(2):1743-1752.

[28] Sisti L, Totaro G, Vannini M, Fabbri P, Kalia S, Zatta A, et al. Evaluation of the retting process as a pre-treatment of vegetable fibers for the preparation of high-performance polymer biocomposites. Ind. Crop Prod. 2016;81:56-65.

[29] Totaro G, Sisti L, Vannini M, Marchese P, Tassoni A, Lenucci MS, et al. A new route of valorization of rice endosperm by-product: Production of polymeric biocomposites. Composites Part B. 2018;139:195-202.

[30] Totaro G, Marchese P, Sisti L, Celli A. Use of ionic liquids based on phosphonium salts for preparing biocomposites by in sit u polymerization. J. Appl. Polym. Sci. 2015;132(35):42467-42475.

[31] Neppalli R, Causin V, Benetti EM, Ray SS, Esposito A, Wanjale S, et al. Polystyrene/ $\mathrm{TiO}_{2}$ composite electrospun fibers as fillers for poly(butylene succinate-co-adipate): Structure, morphology and properties. Eur. Polym. J. 2014;50:78-86.

[32] Zhou W, Wang X, Wang P, Zhang W, Ji J. Enhanced mechanical and thermal properties of biodegradable poly(butylene succinate-co-adipate)/graphene oxide nanocomposites via in situ polymerization. Appl. Polym. Sci. 2013;130(6):4075-4080.

[33] Charlon S, Follain N, Dargent E, Soulestin J, Sclavons M, Marais S. Poly[(butylene succinate)-co-(butylene adipate)]montmorillonite nanocomposites prepared by water-assisted extrusion: role of the dispersion level and of the structuremicrostructure on the enhanced barrier properties. J. Phys. Chem. C. 2013;120(24):13234-13248.

[34] Ray SS, Bousmina M, Okamoto K. Structure and properties of nanocomposites based on poly(butylene succinate-co-adipate) and organically modified montmorillonite. Macromol. Mater. Eng. 2005;290(8):759-768.

[35] Chiu FC. Fabrication and characterization of biodegradable poly(butylene succinate-co-adipate) nanocomposites with halloysite nanotube and organo-montmorillonite as nanofillers. Polym. Test. 2016;54:1-11.

[36] Chiu FC, Hsieh YC, Sung YC, Liang NY. Poly(butylene succinate-co-adipate) green composites with enhanced rigidity: influences of dimension and surface modification of kenaf fiber reinforcement. Ind. Eng. Chem. Res. 2015;54(51):12826-12835.

[37] Seggiani M, Gigante V, Cinelli P, Coltelli MB, Sandroni M, Anguillesi I, et al. Processing and mechanical performances of Poly(ButyleneSuccinate-co-Adipate) (PBSA) and raw hydrolyzed collagen (HC) thermoplastic blends. Polym. Test. 2019;77:105900 (1-10)

[38] Cai L, Qi Z, Xu J, Guo B, Huang Z. Study on the Photodegradation Stability of Poly(butylene succinate-co-butylene adipate)/TiO nanocomposites. J. Chem. 2019;2019, Article ID 5036019, 9 pages.

[39] Kuo DL, Wu TM. Crystallization behavior and morphology of hexadecylamine-modified layered zinc phenylphosphonate and poly(butylene succinate-co-adipate) composites with controllable biodegradation rates. J. Polym. Environ. 2019;27:10-18.

[40] Chen YA, Tsai GS, Chen EC, Wu TM. Thermal degradation behaviors and biodegradability of novel nanocomposites based on various poly[(butylene succinate)-co-adipate] and modified layered double hydroxides. J. Taiwan Inst. Chem. Eng. 2017;77:263270.

[41] Xu Y, Xu J, Liu D, Guo B, Xu X. Synthesis and characterization of biodegradable poly(butylene succinate-co-propylene succinate)s. J. Appl. Polym. Chem. 2008;109(3):1881-1889.

[42] Papageorgiou GZ, Bikiaris DN. Synthesis, cocrystallization, and enzymatic degradation of novel poly(butylene-co-propylene succinate) copolymers. Biomacromolecules 2007;8(8):2437-2449. 
[43] Parcheta P, Datta J. Structure analysis and thermal degradation characteristics of bio-based poly(propylene succinate)s obtained by using different catalyst amounts. J. Therm. Anal. Calorim. 2017;130:197-206.

[44] Umare SS, Chandure AS, Pandey RA. Synthesis, characterization and biodegradable studies of 1,3-propanediol based polyesters. Polym. Degrad. Stab. 2007;92(3):464-479.

[45] Tsai CJ, Chang WC, Chen CH, Lu HY, Chen M. Synthesis and characterization of polyesters derived from succinic acid, ethylene glycol and 1,3-propanediol. Europ. Polym. J. 2008;44(7):2339-2347.

[46] Parcheta P, Datta J. Influence of chemical structure on physicochemical properties and thermal decomposition of the fully biobased poly(propylene succinate-co-butylene succinate)s. Polym. Test. 2020;83:106337(1-16).

[47] Kluge M, Bikiaris DN Robert T. Enhancing the properties of poly(propylene succinate) by the incorporation of crystallizable symmetrical amido diols. Europ. Polym. J. 2019;120:109195(1-10).

[48] Klonos PA, Kluge M, Robert T, Kyritsis A, Bikiaris DN. Molecular dynamics, crystallization and hydration study of Poly(Propylene succinate) based Poly(Ester amide)s. Polym. Test. 2020;186:122056(1-13).

[49] Bikiaris DN, Papageorgiou GZ, Papadimitriou SA, Karavas E, Avgoustakis K. Novel biodegradable polyester poly(propylene succinate): synthesis and application in the preparation of solid dispersions and nanoparticles of a water-soluble drug. AAPS Pharm. Sci. Tech. 2009;10(1):138-146.

[50] Celli A, Marchese P, Sisti L, Dumand D, Sullalti S, Totaro G. Effect of 1,4-cyclohexylene units on thermal properties of poly(1,4cyclohexylenedimethylene adipate) and similar aliphatic polyesters. Polymer Int. 2013;62(8):1210-1217.

[51] Totaro G, Cruciani L, Vannini M, Celli A, Mazzola G, Di Gioia D, et al. Synthesis of castor oil-derived polyesters with antimicrobial Activity. Europ. Polym. J. 2014;56:174-184.

[52] Totaro G, Paltrinieri L, Mazzola G, Vannini M, Sisti L, Gualandi C, et al. Electrospun fibers containing bio-based ricinoleic acid: effect of amount and distribution of ricinoleic acid unit on antibacterial properties. Macromol. Mater. Eng. 2015;300(11):10851095.

[53] Gioia C, Banella MB, Totaro G, Vannini M, Marchese P, Colonna M, et al. Biobased vanillic acid and ricinoleic acid: building blocks for fully renewable copolyesters. J. Renew. Mater. 2018;6(1):126-135.

[54] Tserki V, Matzinos P, Pavlidou E, Panayiotou C. Biodegradable aliphatic polyesters. Part II. Synthesis and characterization of chain extended poly(butylene succinate-co-butylene adipate). Polym. Degrad. Stab. 2006;91(2):377-384.

[55] He Q, Yin S, Sato T. Synthesis and photochemical properties of zinc-aluminum layered double hydroxide/organic UV ray absorbing molecule/silica nanocomposites. J. Phys. Chem. Solids 2004;65(2-3):395-402.

[56] Zhou Q, Verney V, Commereuc S, Chin IJ, Leroux F. Strong interfacial attrition developed by oleate/layered double hydroxide nanoplatelets dispersed into poly(butylene succinate). J. Colloid Interfaces Sci. 2010;349(1):127-133.

[57] Coelho C, Hennous M, Verney V, Leroux F. Functionalisation of polybutylene succinate nanocomposites: from structure to reinforcement of UV-absorbing and mechanical properties. RSC Adv. 2012;2:5430-5438.

[58] Wang X, Zhou J, Li L. Multiple melting behavior of poly(butylene succinate). Europ. Polym. J. 2007;43(8):3163-3170.

[59] Wei Z, Chen G, Shi Y, Song P, Zhan M, Zhang W. Isothermal crystallization and mechanical properties of poly(butylene succinate)/layered double hydroxide nanocomposites. J. Polym. Res. 2012;19:9930(1-10).

[60] Du LC, Qu BJ, Meng YZ, Zhu Q. Structural characterization and thermal and mechanical properties of poly(propylene carbonate)/MgAl-LDH exfoliation nanocomposite via solution intercalation. Compos. Sci. Technol. 2006;66(7-8):913-918.

[61] Costantino U, Bugatti V, Gorrasi G, Montanari F, Nocchetti M, Tammaro L, et al. New polymeric composites based on poly $(\epsilon-$ caprolactone) and layered double hydroxides containing antimicrobial species. ACS Appl. Mater. Interfaces 2009;1(3):668-677.

[62\} Eili M, Shameli K, Ibrahim NA, Yunus WMZW. Degradability enhancement of poly(lactic acid) by stearate-Zn ${ }_{3} A$ I LDH nanolayers. Int. J.

Mol. Sci. 2012;13(7):7938-7951. 
